\title{
Conclusion: Forms of Affirmative Aesthetics
}

Optimism and positivity are often associated with naivety or a lack of critique. On the contrary, negativity may be seen as either leading to fatalism or essential for the production of critical art. Affirmative aesthetics integrate the critique of the present while also producing a complex relational reality that points to other possibilities beyond the status quo, and to alternative futures. This book has argued that affirmative production does not necessarily happen at the narrative level but rather at an aesthetic level. Affirmative forms may indeed remain invisible as affects in the en-deça of visual arts. As Bersani and Dutoit have argued, it is the work of spectators and critics to see and reveal the invisible. If diegesis and narrative are indivisible from representation and filmic form, extented attention to filmic aesthetic may unveil affirmative forms; forms that are critical, transformative, and that may remain hidden if one only looks at diegeses and characters' representaion alone.

To sustain my point further, I would like to briefly compare two films that consider women's relationship to space, power-geometries, and emancipation: Wild (Jean-Marc Vallée 2014) and Roma (Alfonso Cuarón 2018). The focus on a woman character's problematic habitation of space and their U.S.-based production are the only common aspects of these films. On the one hand, Wild seems to show a positive representation of a woman's emancipation, through the protagonist's resolve to overcome

(C) The Author(s) 2020

M. Ceuterick, Affirmative Aesthetics and Wilful Women, https://doi.org/10.1007/978-3-030-37039-8_6 
the difficulties for women to walk into the wild and occupy 'public' spaces. On the other hand, it closes on the neoliberal idea of an individual woman working for and by herself in order to attain her goals, thereby leaving unrecognised the privileged background that has allowed this. The final scene of Wild confirms this interpretation. As the main protagonist Cheryl (interpreted by well-known American actress Reese Witherspoon) visually and metaphorically leaves the woods, through which she has travelled for the last four months and almost the entirety of the film, she reaches and stands on the Bridge of the Gods, which unites the states of Oregon and Washington. Both her final monologue in voice-over and the film's aesthetic emphasise the individual and transcendental (religious) dimensions of her emancipation. The camera's close-up on her feet walking towards the camera do not point to a wilful move forward beyond the duration and spaces of the film, but rather a journey inward that is completed within the character and on the bridge. The character's future marriage and the children that will result from that marriage, which she mentions in voice-over, figure as a neofeminist rehearsal of a gendered and heteronormative history, whereby women's achievements are measured in terms of taking on a gendered and domestic role. Before the conventional black screen that closes the film, the camera closes up on Cheryl from a high angle as she looks up towards the sky and then closes her eyes (suggesting a Christian idea that her mother/God was looking after her from Heaven during her adventures, and that her/His force has been within her all along). This ending reinforces the neoliberal idea that achievement is ultimately individual and to be found within oneself (with the help of God, not socioeconomic privilege). If the diegesis promotes a positive and emancipatory view of women (which the film was critically celebrated for), the filmic forms of this ending scene reveal a certain fatalism in the modification of power-geometries, which is contingent on individual will, heteronormative gender roles, and the 'sacred' advantage of socioeconomic belonging.

Roma has been regarded as displaying the fatalism of class inequality and the impossibility of emancipation from ideological chains (Slavoj Žižek 2019), because the film's indigenous woman protagonist Cleo works as a caretaker of a rich Mexican family. I argue, however, that the aesthetic of the film creates affirmative moments. Long takes of Cleo standing in silence and looking off frame abound in the film; the length of the takes demonstrate that Cleo gets lost in her thoughts. A framing of Cleo looking through a window of the family's house, enclosed between lines, edges, 
and a multiplicity of objects, with the foreground sound of hail falling outside, contrasts with a low angle image of Cleo standing on the balcony of the family's holiday house and a reverse shot showing the object of her vision. The reverse shot shows, fairy lights shining in the night, and produces an audible atmosphere, of ambient sounds of waves, crickets, and distant singing. The length of the take allows the spectators to get lost in their thoughts just as Cleo does. Whereas the first scene of Cleo next to the window emphasised her imprisonment in a precarious situation, the aesthetic of the second scene gives shape to a sensuous self. Following the balcony scene, another lengthy take shows Cleo as she recalls the sound and smell of the village where she grew up. As she points her face towards the sun in the upper-right corner of the frame and enjoys its warmth with her eyes closed, the camera begins a tracking shot towards the right, which extends the direction of her body. Although very little about Cleo is articulated through the diegesis, a micro-analysis of space and the filmic forms reveal aspects of her subjectivity. Rather than a continuous display of positivity, it is the formal suggestion that things could be otherwise that produces moments of affirmative aesthetics. Similarly, when Cleo saves one of the children from drowning, the overwhelming sound of the rough sea and the still image of the entire family surrounding her on the beach afterwards produce the bodily and emotional involvement of Cleo as a member of the family, more so than the relentless and unconditional subservience of the poor, as Žižek asserts. As Cleo admits while sobbing that she never wanted the stillborn child she gave birth to, she blames herself for her death as if her wish engendered divine punishment: 'Yo no la quería, no quería que naciera, pobrecita' ('I did not want her, I did not want her to be born, the poor one', translation mine). Saving Sofi from drowning is just like saving her own baby girl. The composition of the frame and geometrical shape of the family's bodies surrounding Cleo in this scene may recall Théodore Géricault's painting 'Le Radeau de la Méduse/The Raft of the Medusa' (1818-1819); the mise-en-scène annihilates the social hierarchy present within the family and on the Medusa raft, at least for a moment (see Fig. 6.1). In contrast with the closing scene of Wild, the cinematography of the final scene of Roma points to future possibilities. As Cleo hangs up the family's clothes, the camera tilts upwards to film her as she slowly climbs the stairs that lead to the roof but it stays at the level of the house, one of the few times in the film that the camera does not eventually follow the character (see Fig. 6.2). As Cleo exits the frame, she 


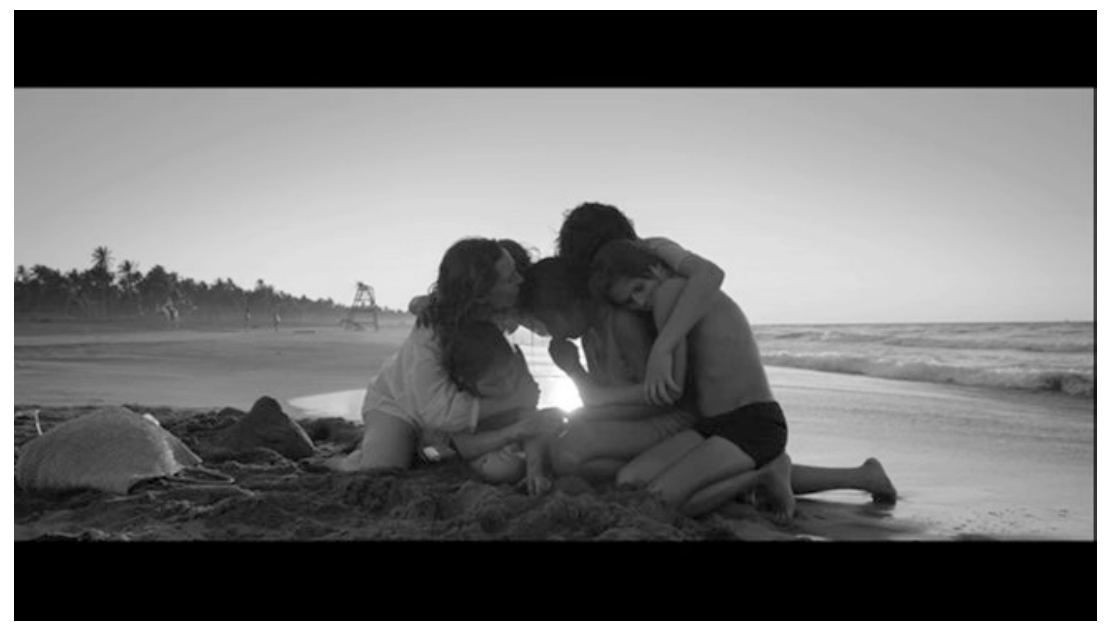

Fig. 6.1 Roma: The family surrounding Cleo as a member of the family

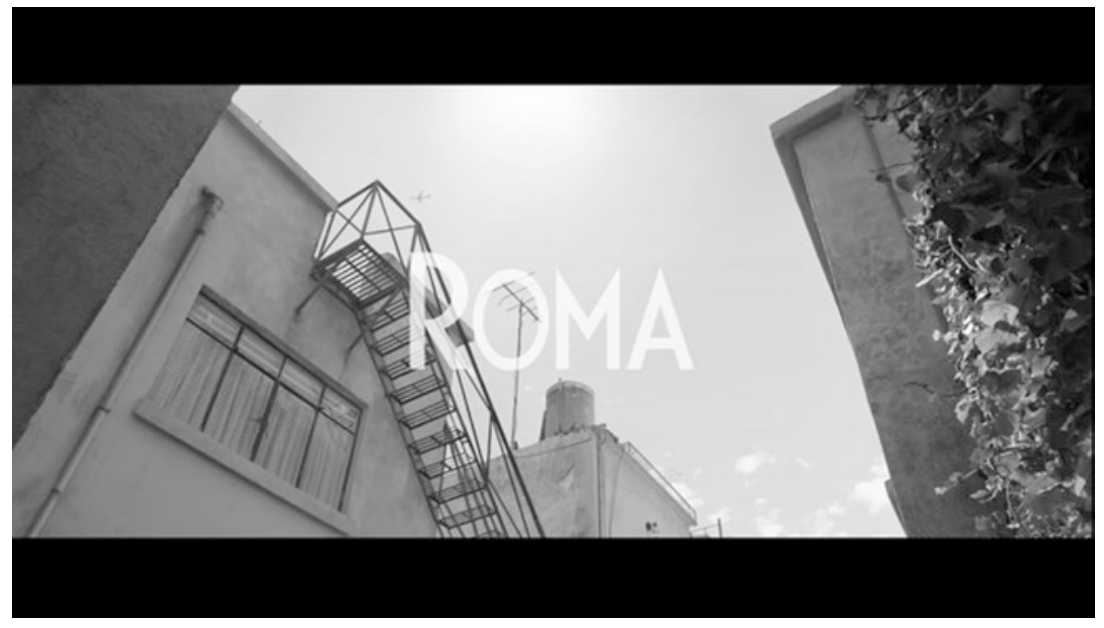

Fig. 6.2 Roma: Ending image after Cleo has left the frame 
penetrates a space that may not be in view yet, but one that she creates for herself, through her embodied habitation. The social realism of the film does not grant an easy access to Cleo's subjectivity (something that other critics have deplored, such as Brody 2018), which is reinforced by her use of the indigenous Mixtec language that the family and the majority of the audience do not grasp. The aesthetic of the film, however, participates in the creation of Cleo's embodied subjectivity in a discreet fashion. The metal bars of the stairs (and the direct sound of Cleo's steps) and the plane in the sky represent at once the bars of Cleo's prison, the unattainable escape from her situation, and the possibilities to reach up, socially and emotionally (if not economically). The deeply low angle of the camera as she leaves the frame and the accentuated sound of the plane and of the singing birds reinforce these symbols as the dedication and the title of the film are superimposed on the still image at the film's end. While the narrative emphasises the negative affects of colonial power-geometries, other filmic forms bring the virtual into the real and present the affirmative multiplicities present within Cleo's life.

While feminist film theory and films such as Wild may formulate a critique, they also indirectly contribute to maintaining women in their conventional place, or rather, out of place (to echo Doreen Massey). Whereas Wild displays the positive affects of travel, it also depicts the class, racial, and gender status quo as somewhat immutable. As Roma critiques the collective negative affects of class disparities (through Cleo's situation and the student protest that indirectly leads to Cleo's stillborn baby), its aesthetic choices also bring affirmative forces to the fore, thereby creating subjects and spaces in continual transformation. Instead of presenting subjects caught in the spiral of gender and race performance, Roma emphasises the timely, contextual, and relational aspects of bodies and spatial habitation. Like the other films examined in this book, Roma works 'with the time and in spite of the time' rather than pursuing 'a quest for meaning', in Braidotti's words $(2011,292)$. The analysis of Messidor and the brief consideration of Wild show us that focusing on the diegesis and narrative success of the characters and their mobility sometimes obscures other aspects of the film, which may be revealed through the reading of affects as forms.

I have suggested that mainstream cinema (chiefly the road movie genre) and the scholarship dealing with space, gender, and cinema participate in 
creating socio-spatial binaries. Such binaries oppose in a seemingly immutable manner masculine with feminine, public with private, and travel with stasis. The analysis of Messidor, a film made in the wake of second wave feminism in Europe, appeared as an adequate point of departure from which to study the conditions that have rendered women's travel difficult and refused them the mobility that generally 'propel the usually male characters along the road of discovery' within the road movie genre (Corrigan 1992, 144). Chapter 2 concluded that the denial of growth for the female protagonists was anchored in the sociocultural gendering of both their bodies and the spaces they intended to inhabit. Women's freedom to fully inhabit space could not be measured in terms of travel, as it could for men. The 'mobility' of women should instead be thought of in terms of how their bodies' micro-relations to space produce affirmative forms. The chapter has introduced the idea that wilfulness takes different forms on screen. In Messidor, it is the insatiable search for mobility, the pause for reflections, and the habitation of space on screen rather than movement through it that produce moments of affirmation.

Affirmative aesthetics finds different models through which cinema suspends the gendering of space, the normative relations of gender and power, and the idea that gender, ethnicity, or sexuality determine subject identities and spatial habitation. Vendredi soir, Wadjda, and Head-On have served as case studies of a transnational narrative cinema - anchored in realism rather than genre - that questions and critiques women's difficult relations to mobility and 'public' spaces and (aesthetically) situate spatial habitation within fluid relations instead of within fixed normative identities. All the films analysed reveal the importance for women to have a space of their own, that is, a certain degree of social, economical, and spatial freedom. In their own ways, the films give form to a collectivity of wilful women. The haptic aesthetic of Vendredi soir converts bodies into lived bodies, and the imaginative and the virtual into the suspension of gender roles and expectations. Wadjda shows the generational and contextual dimensions of wilfulness, and the power of performance and masquerade to avoid being identified as wilful and being forced to comply. In Head-On, performing gender as a cultural form of 'femininity' or cross-dressing turns into the abjection of one's body and a connection to the erotic-as well as deep forms of knowledge and the refusal of conventions. In the four films explored in this book, it is a collective absence of home, of spaces that accommodate the women protagonists, that gives rise to thresholds, liminal subjects, and the recognition of the inadequacies of binary categories. 
Though an examination of different films would have produced different models of affirmative aesthetics, this book has sought to make available an analytical model that may help other scholars develop an affirmative kind of critique, which detaches space and subject identities from the negativity of binaries. A greater variety of cinemas, such as local cinemas not aimed at an international audience, and a greater variety of contextual relations to space, such as those of transgender, lesbian, or ageing bodies, would certainly introduce other reactions to the trauma of not being accommodated. In Bridgette Auger and Itab Azzam's documentary film We Are Not Princesses (2018), exiled bodies, bodies in displacement, refugees living in campspeople always in between, with nowhere to call home-find a temporary home and alleviation to their trauma within movement and artistic production (such as singing or theatre). This is also the case for the transgender woman protagonist in the fiction film Una mujer fantástica (Sebastián Lelio 2017), who has to face constant humilliations and refusals of being granted a place to call home. Similarly, the ending scene of Lelio's earlier film Gloria (2013) uses dance to break with the expectations linked to women of old age. As with Head-On, dance allows the body to unravel through the senses and suspend codes linked to gender, age, 'race', or sexuality.

On screen, wandering off the prescribed path counters the idea of girls and women being 'natural caretakers' or 'happy housewives', just as shown in Marzieh Meshkini's film Roozi ke zan shodam/ The Day I Became a Woman (2000). The resistance to spatial constraints of three generations of wilful women (Hava, Ahoo, and Hoora) takes place through movement: the young Hava goes to play with her male friends on the beach one last time before being housebound because she has turned nine years old and 'become a woman', Ahoo persists in cycling in a competition even when her husband threatens to divorce her because she will not quit, and the old Hoora travels from the countryside to the city with the money of her deceased husband to buy all the domestic appliances she missed out on during her married years. These three women inhabit space in a way that differs from the norm. As wilful women, they will 'what is not present', they march 'with angry feet', and 'put their bodies in the way' of patriarchal imaginaries (Ahmed 2014, 8; 163). As with women who participate in the 'Slut Walks' or 'Reclaim the Night' marches, women's will not to go with the flow involves taking space and making space for themselves in places that do not naturally accommodate them. Instead of offering a lament, the films briefly described here manifest as affirmatively political; while the protagonists recognise the limitations to their freedom, 
the aesthetic forms that their actions take suggest the multiple possibilities of the present and alternative futures.

This leads us to consider another latent aspect of this book, namely the political aspect of art, the possibility that affirmative forms affect how space, subject identities, and bodies are lived and perceived in the material world. In his book Post-cinematic affect, Steven Shaviro borrows Raymond Williams' concept 'structures of feeling' to look at the expressiveness of film: how films give voice to 'ambient, free-floating sensibility that permeates our society today, although it cannot be attributed to any subject in particular' $(2010,2)$. While Shaviro's thinking resonates with Braidotti's affirmative ethics in that it favours transforming forces over genealogies or causes of negative affects, Shaviro rejects the idea that 'media works, or [his] discussion of them, or the reception of them by others, could somehow constitute a form of "resistance"' $(2010,138)$. If Shaviro states that 'aesthetics does not translate easily or obviously into politics', he argues that the role of art is to explore the future, while his role as a critic lies in the affective mapping of films' rearticulation of social processes (2010, 138-139). Affirmative aesthetics and Wilful Women also serves as an affective mapping and a rearticulation process of the ordinary trauma that pulls women in particular in uninhabitable gendered directions. A micro-analysis of how forms and bodies shape affirmative spaces on screen reveals aesthetic navigations of negative affects and their rewriting as productive forces. If aesthetics cannot be directly translated into politics, affirmative films are political insofar as they provide alternatives, albeit sometimes subtly, to disempowered collectivities. ${ }^{1}$

As this book has explored the 'forms of the affects' (as per Brinkema's expression) that give rise to women's habitation of fluid space-time, it has ignored the human body of the spectator that may somewhat live through these affections. If the role of the spectator and the critic is to see the invisible forms of visual arts beyond their characters and diegetic structures, it may also be the role of the spectator to adopt an embodied position: the spectator's 'body [thus becoming] a source not just of individual but of cultural memory' (Marks 2000, xiii). In that case, film viewing would be an embodied experience that affects our spatial imaginary and may ultimately transform collective (cultural) memories of space and the habitation of space itself.

As explored in the introductory chapter through the works of Deleuze, Massumi, Ahmed, Hemmings, Berlant, Dyer, and Brinkema, affects 
function at different interwoven and simultaneous levels. As affects emerge from filmic forms (from the film's aesthetic), it may bring the spectators' bodies in the image, spectators who also affect each other through their co-presence in the movie theatre (creating an 'atmosphere', in Ben Anderson's words, 2009). As Ahmed writes about affective events and situations, the film's body would touch the surface of the viewers' bodies, drawing them into emotional-affective-intellectual experiences, connecting with them by 'moving' them or 'holding [them] in place', and 'giving [them] a dwelling place' $(2004,11)$. Similarly, Vivian Sobchack asserts that the cinematic creates a 'habitable world ... a lived space and active possibility ... a space that is deep and textural, that can be materially inhabited' $(2004,151)$. Sobchack situates the affective experience of cinema in two specific aspects: its preserving of the present 'always presently constituting itself' (146) and the reversibility of the seer and the seen, the onscreen and offscreen (referring too to Merleau-Ponty's reversibility of the touching experience). Sobchack writes:

All the bodies in the film experience-those onscreen and offscreen (and possibly the screen itself) — are potentially subversive bodies ... each arguably becoming the 'grounding body' of sense and meaning since each exists in a dynamic figure-ground relation of reversibility with the others. Furthermore, these bodies also subvert their own fixity from within ... so that meaning, and where it is made, does not have a discrete origin in either spectators' bodies or cinematic representation but emerges in their conjunction. $(2004,67)$

By engaging the body in present and reversible situations, films create textural spaces that can be inhabited, 'lived and re-membered' (Sobchack 2004, 152), and responded to with new possibilities of being-in-the-world and inhabiting the material world. This cultural, individual, and collective mediated habitation of the film's (social) spaces both physically affects our bodies (insofar as affect is contagious Gibbs 2001; Ahmed 2004; Brennan 2004; Probyn 2005) and, in the accumulative dimension of experiences, affects our ways of being in the world, our socio-spatial existence.

From this phenomenological notion of affective (or embodied) spectatorship, two lines of thought emerge. The first one is embedded in Nigel Thrift's work on the collective transmission of affects: 'soaking' space 'with a combination of affects... [that] become bodies of influence', a 
political form $(2008,222)$. In this sense, cinema can be seen as an accumulation of 'like-minded' film bodies potentially provoking political movement by affecting (individual and) collective spectators in a particular way. The second line of thought involves the spectators' micro-relations to, and modification of, space. As seen in Massey and Braidotti's writings, such micro-instances participate in structures of power and may indeed become the foundations for a larger (affirmative) movement. Braidotti calls for affirmative politics as a movement of 'autonomous but mutually connected communities or group-multitudes ... or complex singularities ... engaged in the project of constituting alternative structures', as a result of having been (individually and collectively) negatively affected by unjust politics $(2011,272)$. It may be a valid concern to ask whether the films explored in this book have an impact on spectators' habitation of space, even only at a micro-level, and whether their affective charges would eventually modify existing structures of power.

When Bachelard studies how poetic imaginaries create certain spaces as 'intimate', such as the house, he underlines the 'movement' of the poetic image, which carries the imagination along, brings the reader to experience its language, and potentially creates a new 'nerve fiber' (1994 [1964], xxviii). ${ }^{2}$ The poetic image provides us with an affective experience, and a contact with things; between the 'new image' and the adhesion it invites, there is a transfer of imaginaries between the producer (poet or filmmaker) and receiver (reader or viewer) of the images, an 'inter-subjectivity'; readers thus fully live the poetic image, which takes root in them (Bachelard $1961,15 ; 13 ; 8)$. Applying Bachelard's theory and topoanalytical method to film allow us to recognise how filmic aesthetics produce affective and lived spaces, which may create new connections and accumulatively transform our own habitation of the world (at once affective and embedded within dynamic discourses and power-geometries). As such, every film affects the viewer with more or less intensity through its position as an 'aesthetic object'. Both the poetic and the filmic languages invite an embodied spectatorship; they invite us to enter into contact with the affective and material spaces they create.

As Chapter 1 detailed further, I first and foremost consider films and works of art as maps of social and spatial relations, maps that are dynamic, that may show us different paths and lines of flight, and open our imagination and desires. As Shaviro explains about the post-cinematic media that he himself analyses, they are best regarded as affective maps, which do not just passively trace or represent, but actively construct and perform, 
the social relations, flows, and feelings that they are ostensibly "about" $(2010,6)$. Establishing a transfer of affects between the bodies of the film and the spectators requires further study, as does any attempt to answer the complex question: What does art do to us? I concur with Deleuze and Guattari that 'maps [thereby works of art] are not static representations, but tools for negotiating, and intervening in, social space. A map does not just replicate the shape of a territory; rather, it actively inflects and works over that territory' (Shaviro 2010, 5-6). Post-cinematic media or digital media in a broader sense offers a freer access to a variety of platforms, forms, and languages than cinema has offered and therefore opens the art of cartography to a broader multiplicity of voices.

Virtual reality, augmented reality, locative art, art video, gallery films, and experimental cinema are in some ways denominations of cinema, a confirmation of its constant mutability. Similarly, blogs, electronic literature, and social media are extensions of the written press, the book, and the telephone. While these 'digital media' may only be prolongations or rewritings of codes that already existed, their advanced technology offers a non-linearity, portability, and interactivity, as well as the embodiment of and exchanges between spectators and 'users' that were somewhat restricted by the cinematic apparatus. As a follow-up to this book, it would be worth exploring whether and how the new aesthetic forms developed by 'post-cinematic' media, specifically its juxtapositions, assemblage, and fragmentation, give rise to a different mapping of gender, power, and spatial relations.

\section{Notes}

1. As Lauren Berlant writes in Cruel Optimism, 'Aesthetics is not only the place where we rehabituate our sensorium by taking in new material and becoming more refined in relation to it. But it provides metrics for understanding how we pace and space our encounters with things, how we manage the too closeness of the world and also to have a desire to have an impact on it that has some relation to its impact on us' $(2011,12)$.

I read in Berlant's text the double idea that one's body and sensations transform with aesthetic experiences, and that aesthetics is also a way to measure and cope with the limitations to our freedom, the 'too closeness of the world'. In turn, critical writing and artistic production through film and digital media allow us to take part in the mapping of the world, and thereby, perhaps, have an impact on it. 
2. 'The verse always has a movement, the image flows into the line of the verse, carrying the imagination along with it, as though the imagination created a nerve fiber ... the poetic image furnishes one of the simplest experiences of language that has been lived' (Bachelard 1994 [1964], xxviii).

\section{REFERENCES}

Ahmed, Sara. 2004. The Cultural Politics of Emotion. Edinburgh: Edinburgh University Press.

- 2014. Willful Subjects. Durham: Duke University Press.

Anderson, Ben. 2009. Affective Atmospheres. Emotion, Space and Society 2: 77-81. Auger, Bridgette, and Itab Azzam. 2018. We Are Not Pincesses. Motion Picture. UK/USA: Noerlum Studios, Open Art Productions.

Bachelard, Gaston. 1961. La Poétique de l'espace. 1st edition in 1957. Paris: Presses Universitaires de France.

- 1994 [1964]. The Poetics of Space. Boston: Beacon Press.

Berlant, Lauren Gail. 2011. Cruel Optimism. Durham: Duke University Press.

Bersani, Leo, and Ulysse Dutoit. 2004. Forms of Being: Cinema, Aesthetics, Subjectivity. London: BFI Publishing.

Braidotti, Rosi. 2011. Nomadic Theory: The Portable Rosi Braidotti. Chichester: Columbia University Press.

Brennan, Teresa. 2004. Transmission of Affect. London: Continuum.

Brody, Richard. 2018. There's a Voice Missing in Alfonso Cuarón's "Roma". The New Yorker (Online), December 18. Retrieved on 20 Aug 2019 from https:// www.newyorker.com/culture/the-front-row/theres-a-voice-missing-in-alfonsocuarons-roma

Corrigan, Timothy. 1992. A Cinema Without Walls: Movies and Culture after Vietnam. London: Routledge.

Cuarón, Alfonso. 2018. Roma. Motion Picture. Mexico/USA: Netflix.

Gibbs, Anna. 2001. Contagious Feelings: Pauline Hanson and the epidemiology of Affect, Australian Humanities Review 24. Retrieved on 9 Oct 2019 from http://australianhumanitiesreview.org/2001/12/01/contagious-feelingspauline-hanson-and-the-epidemiology-of-affect/

Géricault, Théodore (1818-1819) Le Radeau de la Méduse [Oil on Canvas]. Musée du Louvre, Paris.

Lelio, Sebastián. 2013. Gloria. DVD. Chile/Spain: Fabula.

. 2017. Una mujer fantastica [A Fantastic Woman]. Motion Picture. Chile/Germany/Spain/USA: Participant Media.

Marks, Laura U. 2000. The Skin of the Film: Intercultural Cinema, Embodiment, and the Senses. Durham/London: Duke University Press.

Meshkini, Marzieh. (2000). Roozi ke zan shodam [The Day I Became a Woman]. DVD. Iran: Makhmalbaf Productions. 
Probyn, Elspeth. 2005. Blush: Faces of Shame. Minneapolis: University of Minnesota Press.

Shaviro, Steven. 2010. Post-Cinematic Affect. Winchester/Washington, DC: 0 [zero] Books.

Sobchack, Vivian. 2004. Carnal Thoughts: Embodiment and Moving Image Culture. Berkeley/Los Angeles/London: University of California Press.

Thrift, N.J. 2008. Non-representational Theory: Space, Politics, Affect. New York: Routledge.

Vallée, Jean-Marc. 2014. Wild. DVD. USA: Fox Searchlight Pictures.

Žižek, Slavoj. 2019. Roma Is Being Celebrated for All the Wrong Reasons. Essay Online. Retrieved on 21 Aug 2019 from https://blogs.spectator.co. uk/2019/01/roma-is-being-celebrated-for-all-the-wrong-reasons-writesslavoj-zizek/

Open Access This chapter is licensed under the terms of the Creative Commons Attribution 4.0 International License (http://creativecommons.org/licenses/ by $/ 4.0 /)$, which permits use, sharing, adaptation, distribution and reproduction in any medium or format, as long as you give appropriate credit to the original author(s) and the source, provide a link to the Creative Commons licence and indicate if changes were made.

The images or other third party material in this chapter are included in the chapter's Creative Commons licence, unless indicated otherwise in a credit line to the material. If material is not included in the chapter's Creative Commons licence and your intended use is not permitted by statutory regulation or exceeds the permitted use, you will need to obtain permission directly from the copyright holder.

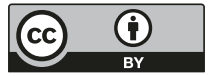

